\title{
A prospective clinical, cost and environmental analysis of a clinician-led virtual urology clinic
}

\author{
S Miah ${ }^{1,2, *}$ C Dunford ${ }^{1, *}$, M Edison ${ }^{1}$, D Eldred-Evans ${ }^{3}$, C Gan $^{1}$, TT Shah ${ }^{1,3}$, P Lunn $^{1}$, \\ M Winkler ${ }^{1}$, HU Ahmed ${ }^{1,5}$, N Gibbons ${ }^{1}$, D Hrouda ${ }^{1}$
}

${ }^{1}$ Department of Urology, Imperial Healthcare NHS Trust, Charing Cross Hospital, London, UK

${ }^{2}$ Division of Surgery and Interventional Science, University College London, London, UK

${ }^{3}$ Division of Surgery, Department of Surgery and Cancer, Faculty of Medicine, Imperial College

London, London, UK

*Both are first joint authors

\section{ABSTRACT}

INTRODUCTION A virtual clinic is a form of telemedicine where contact between clinical teams and patients occur without face-toface consultation. Our study aims to quantify the clinical, financial and environmental benefits of our virtual urology clinic.

MATERIAL AND METHODS We collected data prospectively from our weekly follow-up virtual clinic over a continuous four-month period between July and September 2017.

RESULTS In total, we reviewed 409 patients. Following virtual clinic consultation, $68.5 \%$ of our patients were discharged from further follow-up. The majority of our patients (male 57.7\%, female 55.5\%) were of working age. The satisfaction scores were high, at $90.1 \%$, and there were no reported adverse events as a result of using the virtual clinic. Our calculated cost savings were $£ 18,744$, with a predicted 12 -month cost saving of $£ 56,232$. The creation of additional face-to-face clinic capacity has created an estimated 12-month increase in tariff generation for our unit of $£ 72,072$. In total, 4623 travel miles were avoided by patients using the virtual clinic, with an estimated avoided carbon footprint of $0.35-1.45$ metric tonnes of $\mathrm{CO}_{2 \mathrm{e}}$, depending on mode of transport. Our predicted 12-month avoided carbon footprint is 1.04-4.04 metric tonnes of $\mathrm{CO}_{2 \mathrm{e}}$.

CONCLUSIONS Our virtual clinic model has demonstrated a trifecta of positive outcomes, namely, clinical, financial and environmental benefits. The environmental importance and benefits of a virtual clinic should be promoted as a social enterprise value when engaging stakeholders in setting up such a urological service. We propose the adoption of our virtual clinic model in those urological units considering this method of telemedicine.

\section{KEYWORDS}

Urology virtual clinic - Telemedicine - Environment - Carbon footprint

Accepted 2 June 2018

CORRESPONDENCE TO

Saiful Miah, E: saiful.miah@ucl.ac.uk

\section{Introduction}

The methods used to deliver health care to patients are rapidly evolving. Telemedicine has been defined as the use of medical information that is exchanged from one site to another through electronic communication to improve a patient's health. ${ }^{1}$ A virtual clinic is a form of telemedicine where contact between clinical teams and patients occurs without face-to-face consultation. Telemedicine is increasingly being employed both in primary and secondary health care across the world. Its use is predicted to further expand due to a combination of continuous innovation in the consumer technology market, advancement in electronic health records, projected shortages in the healthcare workforce and the growth of consumerism in healthcare. ${ }^{1}$
The increasing number of outpatient referrals, many of which require follow-up appointments, invariably leads to longer waiting times for urological reviews, which can ultimately result in delays in diagnosis and treatment. One such method to clinically and fiscally accommodate the increased service demands on urology departments is to incorporate telemedicine strategies such as a virtual clinic.

The healthcare industry has a social and environmental accountability for the carbon footprint it generates. It is estimated that in the United States the aggregate carbon footprint of the healthcare sector contributes to $8 \%$ of that nation's greenhouse gas emissions and in the UK this figure is $3-4 \% .^{2,3}$ Globally, healthcare providers have been set targets to ensure the increasing implementation of ecofriendly options when delivering their services. In the UK, 
MIAH DUNFORD EDISON ELDRED-EVANS GAN SHAH LUNN IWINKLER AHMED GIBBONS HROUDA
A PROSPECTIVE CLINICAL, COST AND ENVIRONMENTAL ANALYSIS OF A CLINICIAN-LED VIRTUAL UROLOGY CLINIC the NHS reduced its carbon emissions by $11 \%$ between 2007 and 2015, exceeding the $10 \%$ target set in $2009 .^{4}$ More recently, however, it has been predicted that the NHS is unlikely to deliver the long-term goals in combating climate change with the current pace of implemented changes. ${ }^{4}$

The objective of our study was to prospectively quantify the environment, clinical and financial benefits of our virtual urology clinic service.

\section{Materials and methods}

\section{Study design and participants}

Our study was reviewed and approved by our local audit and service evaluation department (Imperial College Healthcare NHS Trust, London, UK: Project registration number 2017-184). We prospectively collected data from all our 33 follow-up virtual clinics over a continuous fourmonth period between July and October 2017. Box 1 provides a summary for the list of indications for virtual clinic review. The tool used was a teleconsultation using either the patient's landline or mobile cellular telephone number. All patients selected for virtual clinic follow-up were made aware of this method of follow-up consultation in their prior face-to-face clinical encounter and agreed to use it. They were provided a timeframe for this contact during the initial consultation with the clinician and were given the number of our administrative team to raise any concerns regarding their future virtual consultation. Patients were made aware of the protocol if they were not contactable on multiple attempts. Patients scheduled for results review that we were unable to contact were provided with a letter explaining the result and plan of action; this was sent to both the patient and their general practitioner. Alternatively, the patient was offered a face-to-face clinic. Each virtual clinic was undertaken by a middle-grade urologist under the supervision of a named consultant, who was always available for any clinical concerns and queries.

\section{Box 1 List of the indications for virtual clinic review.}

Venous biochemistry review

Venous haematology review

Radiological investigation review

Symptom review

Pathology review

\section{Clinical outcomes analysis}

The recorded outcomes for each patient following their virtual clinic was selected from the following four options: discharged, rebook virtual clinic, discuss at multidisciplinary team meeting or book for face-to-face clinic. At the end of each virtual consultation, each patient that we were able to contact was asked to rate their satisfaction level of our service using a five-point Likert scale (1: very unhappy; 2: unhappy; 3: neither happy or unhappy; 4: happy; 5: very happy). A review of our departmental adverse events and complaints log was performed following a minimum four-month period after each virtual consultation took place. This was to assess if any of our virtual clinic cohort of patients had an adverse event.

\section{Cost-outcomes analysis}

Cost analysis was performed using the 2017-18 NHS national tariff workbook. ${ }^{5}$ In short, the charge to NHS Clinical Commissioning Group for a face-to-face new and follow-up consultation cost is $\mathfrak{£ 1 7 3}$ and $\mathfrak{£ 6 6}$ respectively for each patient. This tariff included the market forces factors applicable to our institution. The cost for each virtual clinic was calculated at $£ 250$ per session, with each session having a list of 12-13 patients. The administrative costs for each virtual clinic was two hours of administrative tasks (NHS band 3 pay scale 2017-18) and each incurs a 25\% surcharge for corporate overhead costs. These administrative costs were identical for running a face-to-face clinic.

\section{Environmental outcomes analysis}

We calculated a range for the carbon footprint generated depending on the patient's potential mode of travel: underground train or a car. For assumed journeys by car, we selected a 1800 cc petrol engine car, which represents the average engine capacity and type of fuel for vehicles in the UK according the Department for Transport. ${ }^{6}$

Total travel distance for each patient was calculated on a round-trip from the patient's residential address to our institution. These travel distances were calculated using Google Maps and selecting the car as the mode of travel. The estimated carbon footprint was calculated using the calculator supplied by Carbon Footprint. The number of trees required to offset the carbon footprint generated by an alternative face-to-face clinic was calculated using an established agricultural algorithm which is the need to plant five trees for one to mature into an adult (Trees for the Future; www.trees.org).

\section{Data collection and analysis}

All data and patient responses were entered into an SPSS database (SPSS Statistics version 24).

\section{Results}

\section{Demographics}

In total, we reviewed 409 patients over our four-month assessment period (Table 1). This included 281 male patients (mean age 60 years) and 128 female patients (mean age 61.5 years. The majority of our patients, male and female ( $n=162,57.7 \%$, and $n=71,55.5 \%$, respectively) were of working age.

\section{Patient outcomes}

The majority of our patients $(68.5 \%, n=280)$ were discharged from further follow-up (Figure 1). Thirteen per cent of our patients were given an appointment for a faceto-face clinic $(n=53)$, with the remainder either having another future virtual clinic booked $(16.1 \%, n=66)$ or being listed for discussion at a multidisciplinary team 
MIAH DUNFORD EDISON ELDRED-EVANS GAN SHAH LUNN IWINKLER AHMED GIBBONS HROUDA
A PROSPECTIVE CLINICAL, COST AND ENVIRONMENTAL ANALYSIS OF A CLINICIAN-LED VIRTUAL UROLOGY CLINIC

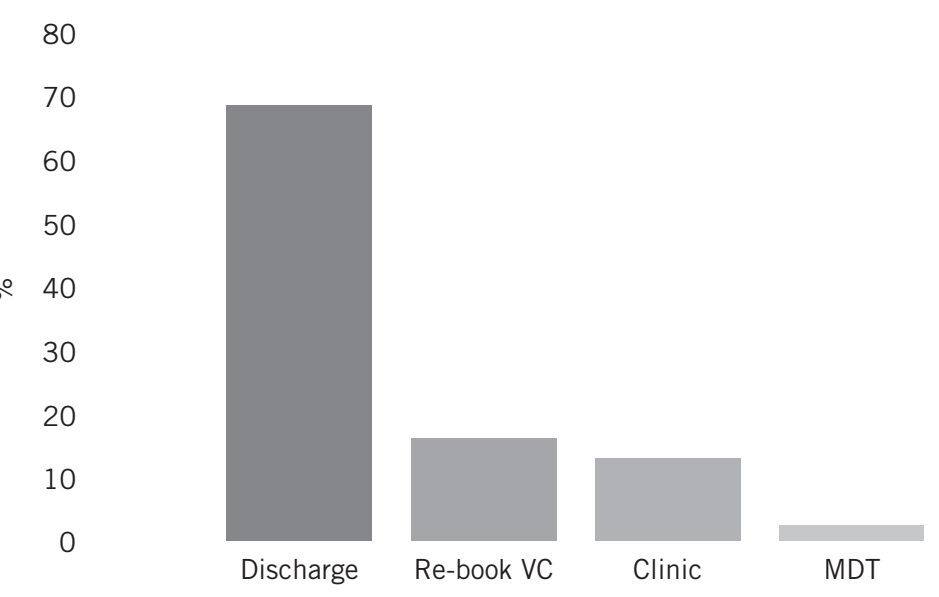

Figure 1 Clinical outcomes of virtual clinic (VC); Clinic = rebook face-to-face clinic; MDT = discuss at multidisciplinary team meeting.

Figure 2 Patient satisfaction level of our service using a five-point Likert scale (1: very unhappy, 2: unhappy, 3: Neither happy or unhappy, 4: happy, 5: very happy).

meeting $(2.4 \%, n=10)$ prior to a decision around their clinical outcome. Patient satisfaction with our service (defined as very happy or happy) was at $90.5 \%$ (Figure 2). Dissatisfaction (defined as very unhappy or unhappy) was at $2.8 \%$. No patients were recorded or identified as undergoing an adverse events as a direct result of their virtual consultation. No patients were recorded as having made a formal complaint siting their virtual consultation as a cause.

\section{Cost outcomes}

The cost of the virtual clinic was $£ 8,250$ over the fourmonth period. The face-to-face follow-up clinic opportunity

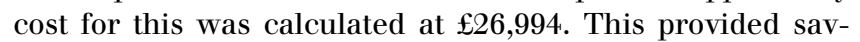

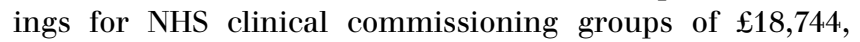
making a predicted 12-month cost saving of $£ 56,232$.

\section{Environmental outcomes}

In total, 4623 travel miles were avoided by patients. The median travel distance avoided for each patient was 3.8 miles. The estimated avoided carbon footprint due to travel was calculated $0.35-1.45$ metric tonnes of $\mathrm{CO}_{2} \mathrm{e}$. Our predicted 12-month avoided carbon footprint is 1.05-4.35 metric tonnes of $\mathrm{CO}_{2} \mathrm{e}$. The number of trees that would need to be planted to offset carbon production from this travel would be 1.75-7.25 trees. The number that would need to be planted to offset our higher estimate of the predicted 12-month carbon production would be 21.75 trees.

\section{Discussion}

Our virtual clinic model has delivered positive fiscal outcomes without compromising on patient care and 
satisfaction. Our study is also the first to report and quantify the environmental benefits of a virtual urological clinic.

The only other study to report on the outcomes of their virtual urological clinic was by Browne et al. ${ }^{7}$ Using a smaller cohort of patients, this group reported that using a virtual clinic was a failsafe mechanism for reviewing investigation results. Our virtual clinic differed, as we included a wider clinical indication that included symptom review. Our virtual clinic had a significantly higher discharge rate of $68.5 \%$ compared with Browne et al's $10.1 \%{ }^{7}$

Our model not only demonstrates a fiscal saving for NHS clinical commissioning groups and, ultimately, for the UK taxpayer but it is also an opportunity for individual urological units to generate a greater income for their respective departments. By streamlining our follow-up pathway with a virtual option, we created more face-to-face clinic capacity that could be used for the review of new patients. This benefit can be measured both clinically and financially for our department. The additional tariff received from our local clinical commissioning groups for the review of each new-referral in comparison with a followup review is significantly higher, at $£ 107$. Our unit now has the opportunity to use this additional clinic capacity for new patients, generating a greater income for our department. In this four-month period at least $84.6 \% \quad(n=346)$ patients were either discharged or given another virtual clinic appointment. If this additional face-to-face clinic capacity were to be employed for the assessment of new patient referrals, only then we could accommodate 231 of this alternative type of patient consult. This would generate an additional tariff of $£ 24,024$ for our department (predicted 12-month tariff generation of $£ 72,072$; Table 2). The tariff for follow-up clinics has also been reduced, by approximately $30 \%$ in the past year across specialties, making our model an option to offset this potential income loss for surgical departments. ${ }^{5}$

The high satisfaction rate of $90.5 \%$ in this study can be potentially explained by the fact that all patients were made aware that such a clinical encounter would take place. We believe that a real-time contact with patients is important to provide the them an opportunity to raise any concerns and queries directly with a clinician. We also believe by offering that opportunity we are reducing further potential burden on primary care who may be contacted by patients from letter only contacts. With more than $50 \%$ of our patient cohort being of working age, a teleconsultation can reduce the disruption of patients' working pattern and commitments that is generally associated with a face-to-face consultation. Measuring the benefits of this potential increase in economic productivity is outside the scope of this project. However, the adoption of virtual clinics is one such method that has been highlighted as delivering healthcare to patients without detrimentally affecting a nation's gross domestic output. ${ }^{8}$

It has been highlighted that healthcare systems are not prepared for the clinical risks that are posed by climate change. ${ }^{9}$ Collectively, all those responsible for delivering health care have a responsibility to mitigate rising global $\mathrm{CO}_{2}$ levels by opting for and promoting alternative carbon reducing services.

The NHS accounts for $5 \%$ of all road transport emissions in the UK. ${ }^{10}$ This has resulted in a call for the NHS to urgently introduce measures to reduce its energy consumption and emission of greenhouse gases, including reducing the amount of travel by patients. ${ }^{10}$ This could be accomplished with a pan-specialty drive to use our urological virtual clinic model and incorporating it into the follow-up pathway of patient care.

The main arguments against using forestry as a means to mitigating the greenhouse effect are that it is a limited short-term measure, unsustainable in the long-term and it may potentially be used as an excuse not cut down the combustion of fossil fuels. ${ }^{11}$ It has been estimated that the scale of reforestation required to make a long-term impact of atmospheric $\mathrm{CO}_{2}$ reduction would require forestation of a land mass two to three times as large as India to start the process. $^{12}$ Instead, limiting anthropogenic emissions of $\mathrm{CO}_{2}$ should be the primary way of reducing atmospheric $\mathrm{CO}_{2}$ levels.

The total travel distance avoided was calculated at 4623 travel miles. This is a driving distance equivalent from London to Kabul in Afghanistan. Poor air quality in large urban cities, such as London where our institution is based, is also now considered to be a significant public health problem. ${ }^{13}$ It has been estimated that a baby born in London in 2010 who was exposed to the air quality in 2010 for its entire life would lose 2-2.2 years of life. ${ }^{14}$ This reduction in life expectancy is potentially greater than certain prostate cancer diagnoses. ${ }^{15}$ Adopting policies to improve local air quality is an important measure all clinical units and particularly urban ones, should undertake to reduce the cardiopulmonary morbidity and mortality associated with poor air quality. ${ }^{13}$

\section{Study limitations}

Our environmental calculation assumed that all patients would have either used public transport or driven in a car to attend a face-to-face consultation. We understand that a proportion of our virtual clinic patient cohort may have cycled or walked to their appointment. Our satisfaction score was subject to interviewer bias as this was assessed at the end of the virtual consultation by the clinician conducting the consult. Our carbon offsetting calculation is only an estimate and our tree-planting calculation is dependent on geographical area. The wider message that must be taken from this project is the environmental consensus that planting tress is not a sustainable or robust way of counter-acting our carbon-footprint. Instead our strategy should be limiting the production of our greenhouse gases. This analogy can be paralleled with the 'prevention is better than cure' statement that we are all familiarised within our clinical lives and should be implemented in our day-to-day environmental practice. 
MIAH DUNFORD EDISON ELDRED-EVANS GAN SHAH LUNN IWINKLER AHMED GIBBONS HROUDA
A PROSPECTIVE CLINICAL, COST AND ENVIRONMENTAL ANALYSIS OF A CLINICIAN-LED VIRTUAL UROLOGY CLINIC

\section{Conclusion}

To conclude, our virtual clinic model has demonstrated a trifecta of positive outcomes namely clinical, financial and environmental benefits. This was delivered without compromising on patient care and satisfaction. The environmental importance and benefits of a virtual clinic should be promoted as a social enterprise value when engaging stakeholders in setting up such a urological service.

\section{References}

1. Tuckson RV, Edmunds M, Hodgkins ML. Telehealth. N Engl J Med 2017; 377 (16): 1,585-1,592.

2. Chung JW, Meltzer DO. Estimate of the carbon footprint of the US health care sector. JAMA 2009; 302(18): 1,970-1,972.

3. Public Health England. NHS, Public Health and Social Care Carbon Footprint 2012. Cambridge: Sustainable Development Unit; 2014.

4. Kmietowicz Z. NHS hits target on reducing carbon emissions. BMJ 2016; 352: i587.

5. NHS Improvement. 2017/18 and 2018/19 National Tariff Payment System. London: NHS Improvement; 2016.
6. Driver and Vehicle Licensing Authority. Vehicle Licensing Statistics: 2013. London: Department for Transport; 2014

7. Browne C, Davis NF, Mac Craith ED et al. Prospective evaluation of a virtual urology outpatient clinic. Ir J Med Sci 2018; 187(1): 251-254.

8. McKirdy A, Imbuldeniya AM. The clinical and cost effectiveness of a virtual fracture clinic service: an interrupted time series analysis and before-and-after comparison. Bone Joint Res 2017; 6(5): 259-269.

9. lacobucci G. NHS is unprepared for risks posed by climate change, warn leading UK health bodies. BMJ 2016; 352: i1781.

10. Mayor S. NHS should bring in measures to reduce its carbon footprint, BMA says. BMJ 2008; 336(7647): 740.

11. Cannell MGR. Growing tress to sequester carbon in the UK: answers to some common questions. Forestry 1999; 72(3): 237-247.

12. Smith PD, Davis SJ, Creutzig F et al. Biophysical and economic limits to negative $\mathrm{CO}_{2}$ emissions. Nat Climate Change 2016; 6: 42-50.

13. Kelly FJ, Fussell JC. Air pollution and public health: emerging hazards and improved understanding of risk. Environ Geochem Health 2015; 37(4): 631-649.

14. Treharne E. Improving Air Quality in London. London: Greater London Authority 2016.

15. Miah S, Ahmed HU, Freeman A et al. Does true Gleason pattern 3 merit its cancer descriptor? Nat Rev Urol 2016; 13(9): 541-548. 